\title{
Pasado, presente y futuro de las investigaciones sobre el mundo púnico: Una revisión ante el nuevo Milenio.
}

\author{
Fernando Prados Martínez \\ Universidad Autónoma de Madrid
}

\section{Resumen}

Ahora que iniciamos un nuevo siglo, la arqueología púnica cuenta con más de cien años de historia. En el presente artículo se va a tratar de realizar un recorrido a lo largo de la historia de las investigaciones sobre el mundo púnico así como de establecer un estado de la cuestión del desarrollo de esta disciplina y su posición de cara al futuro.

\section{Resumé}

L'archéologie punique a déjà plus d'un siecle d'histoire. Dans cet étude, on va faire un bilan sur l'histoire des recherches scientiphiques sur le monde punique et sur certaines perspectives generaux et l'avenir de cette discipline archéologique.

\section{INTRODUCCIÓN}

En este trabajo vamos a realizar un recorrido a lo largo de más de 150 años de estudios históricos sobre el mundo cartaginés. Para su realización nos hemos encontrado ante numerosos problemas, derivados, fundamentalmente, de la escasez de estudios historiográficos realizados en profundidad sobre este periodo cultural. La cultura púnica, sin duda, ha tenido un trato desigual en relación a otras disciplinas que podríamos definir como "hermanas" metodológica y cronológicamente hablando. Se trata por supuesto de aquellas que conforman el mundo "clásico", esto es, las conocidas como Arqueología de Grecia y Arqueología de Roma. Si las investigaciones sobre la cultura de Cartago, la "madre mediterránea" que definieron ya hace años, autores de la talla de Sabatino Moscati y Enrico Acquaro fueron tardías, es decir, se organizaron bien entrado el siglo XIX, éstas fueron, además, muy escasas. Además, pese a que la disciplina historiográfica púnica ha evolucionado de forma paralela al resto de los estudios historiográficos sobre la Antigüedad y ha pasado por las mismas "reformas", estructuraciones y variaciones en su enfoque, éstas han sido mucho más lentas y han tenido un nivel de incidencia bastante inferior.

Si para el caso del mundo romano tenemos bien marcadas las fases culturales de sus estudios historiográficos y los avances científicos e interpretativos que se han ido sucediendo desde el Renacimiento, para el caso cartaginés, estas cuestiones son mucho más difusas y, en muchos de los casos, están aún por definir. Este dato, desde luego, viene a corroborar que la arqueología púnica es una disciplina aún joven y en proceso de formación. Además, tiene a su favor la posibilidad de apoyarse en los modelo teóricos aplicados para las otras grandes culturas del mediterráneo occidental y ajustarlos a su medida, según conveniencia.

Uno de los principales problemas es la generalizada opinión por parte de los investigadores de incluir el mundo púnico dentro del periodo "Protohistórico". De aquí parten muchas de las dificultades, ya que la cultura cartaginesa evolucionó de forma coetánea al mundo romano y nadie duda que éste se encuadre, historiográficamente hablando, en fases "históricas". La bruma que ha cubierto durante años el conocimiento de la historia de Cartago ha originado que su civilización se enmarque dentro de aquellas "protohistóricas", o, lo que es lo mismo, entre aquellas que, sin tener definida la escritura (siendo éste el rasgo identificativo que marcó la incursión o no dentro de la "Historia") convivieron con pueblos que sí la conocían. Es evidente que el mundo 
púnico nació ya con su propia escritura, si tenemos en cuenta que en su origen confluyen tres sociedades culturalmente avanzadas como son la fenicia (con claros influjos egipcios), la griega y la líbica-beréber. Los problemas de la falta de datos derivan de la no conservación de los textos y la literatura en lengua púnica, de la que tenemos constancia a través de las fuentes. Bueno es traer aquí a colación el tratado agronómico del cartaginés Magón, empleado profusamente en el mundo latino por autores de la talla de Varrón, Columela e incluso Virgilio, aunque éste lo negase (Prados Martínez, 2000b, 52):

"...Praecepta rusticationis, quae
plurima tradiderint Poeni
ex Africa scriptores."

Columela, De Re Rustica, I, 1, 6.

Hos rei rusticae scriptores nobilitate

Mago Carthaginiensis praeterit.

Varrón, Rerum rusticarum libri I, 1, 10.

En sentido convencional, el término de "primera historia" o Protohistoria se aplica al momento en que una sociedad empieza a tener contacto con la escritura (Gutiérrez Lloret, 1997, 42). Parece, pues, que el término designa un concepto transicional y regional, ya que la escritura no fue un fenómeno universal y la cronología de su utilización varió enormemente de unas zonas a otras. En el caso que nos ocupa, en cambio, la falta de textos -por razones eminentemente históricas- sumió a la cultura cartaginesa en la más "profunda" de las protohistorias.

Por otra parte, la cuestión de la falta de documentación literaria cartaginesa se acrecentó con la falta de descubrimientos de monumentos púnicos espectaculares, lo que sumó, aún más si cabe, a la civilización púnica en el olvido. También el interés constante de los historiógrafos griegos y latinos en menospreciar cualquier cosa procedente de Cartago o de su entorno y de su imperio, tampoco ayudó demasiado, sobre todo si tenemos en cuenta que la historiografía medieval y posterior bebió directamente de las fuentes históricas grecolatinas. De todas formas, de estos asuntos nos ocuparemos algo más adelante con mayor detenimiento.

Así, con todo esto, parece lógico que los estudios históricos sobre Cartago y su civilización tuviesen unos difíciles comienzos. Difíciles a excepción de una importante anotación: la propia desdicha, la idiosincrasia de este pueblo vencido, arrasado y olvidado provocó el interés de algunos personajes cultos de finales del siglo
XVIII, precisamente los primeros romanticistas y los orientalistas que vieron en esta civilización un espejo en el que reflejar sus sentimientos internos, su propia "ruina vital".

\section{Marco CRONOLÓgico E histórico: aproximación al MUNDo de Cartago}

Cartago, la ciudad origen de todo el proceso cultural, desde mediados del siglo VI a.C. (fecha de la toma de Tiro por Nabucodonosor de Babilonia) disfrutó de un auténtico despegue económico y político como gran polis de carácter comercial, que fue adquiriendo importancia a través de una política exterior tremendamente agresiva, que se encaminó siempre a facilitar el control de las rutas y de los territorios que más interesaron para la empresa económico-comercial.

El siglo VI a.C. supuso la transformación del modelo económico y social que había permanecido en las franjas costeras del Mediterráneo Occidental desde la llegada de los primeros colonos fenicios, en el siglo VIII a.C. A la crisis generalizada de todo el sistema, con la caída de Tiro como causa -para algunos, lo suficientemente remota como para no tener apenas incidencia(Alvar, 1991, 24 y ss.) hay que sumar una serie de sucesos coincidentes cronológicamente en Occidente, que tuvieron una trascendencia mayor si cabe, como el colapso del sistema económico de Tartessos, con el abandono del comercio de metales y el decrecimiento de la producción que se aprecia en Gadir, así como también con los sucesivos abandonos de centros poblacionales desde el 600 a.C. por todo el Mediterráneo occidental, que supusieron la total independencia de Cartago, que rápidamente se puso al frente de todas las fundaciones hermanas tirias que sobrevivían aún. Toda esta transformación se manifestó con el despegue de Cartago, como ciudad en la vanguardia de todo el nuevo sistema económico del Mediterráneo.

La aparición de esta ciudad norteafricana y su posición hegemónica no conllevó, al menos en principio, grandes movimientos de población (se mantuvo un amplio contingente de población de origen fenicio en las principales fundaciones semitas arcaicas). Sí se llevaría a cabo, por el contrario, un trasvase de población a pequeña escala, a nivel de elites gobernantes procedentes del norte de África, con lo que afloró el elemento semita como rasgo distintivo. Cartago supo sobreponerse rápidamente a la crisis de todo el sistema y se aprovechó de tal manera que se colocó al frente de todas estas ciudades. Estas cuestiones conllevaron la adopción por parte de la mayor parte de las poblaciones de origen feni- 


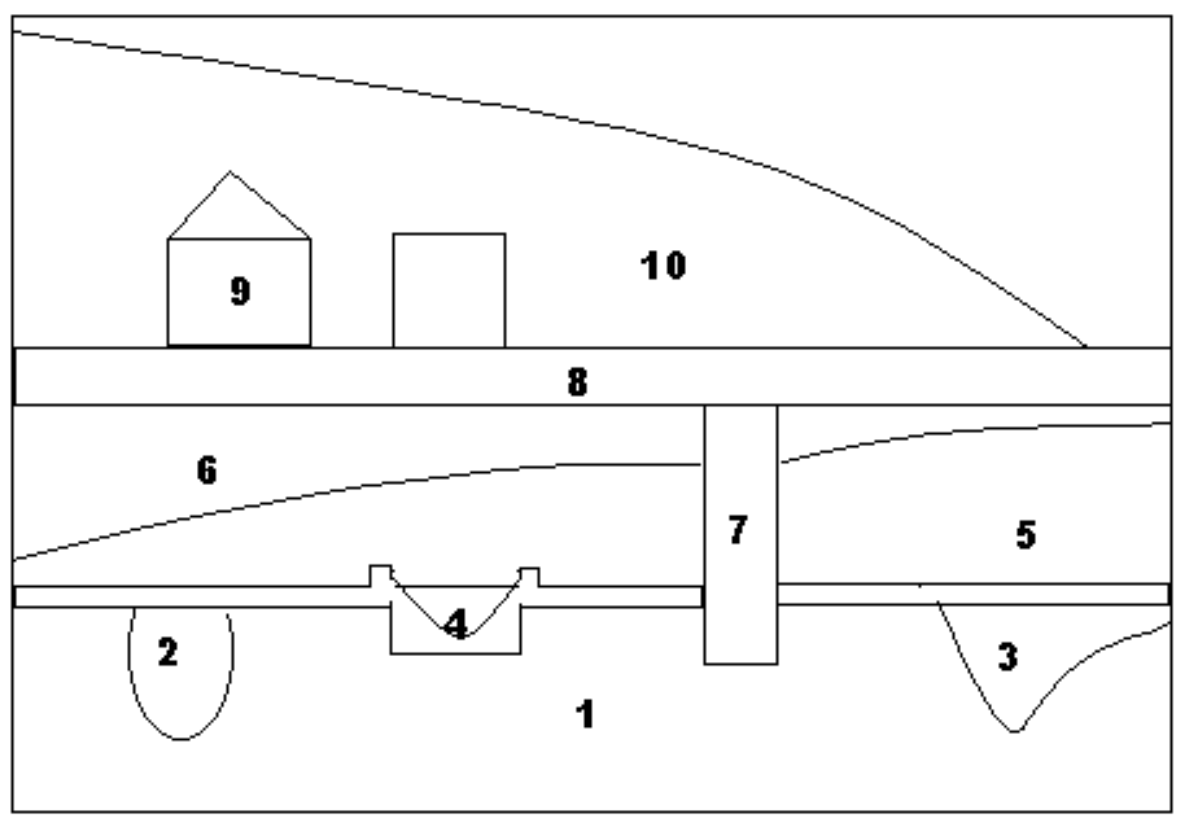

Estratigrafía clásica de Cartago en la zona de la "Acrópolis de Byrsa": 1. Nivel Geológico. 2. Necrópolis fenicia (VIII a. C.). 3. Talleres Metalúrgicos (V-III a. C.). 4. Barrio púnico (III-II a. C.) 5. Derrumbe (146 a. C.). 6. Relleno. 7. Cimentación del foro (II-I a. C.). 8. Nivel de uso romano. 9. Construcciones romanas. 10. Arrasamiento moderno.

cio de un modo de vida sociopolítico definido como púnico, que se erigió de una manera simultánea en todo el Mediterráneo.

La presencia púnica en Ibiza, Sicilia y Cerdeña, también en el siglo VI a.C., coincidió cronológicamente con lo anteriormente mencionado; en Sicilia, a principios del siglo VI a.C., se inició una oleada de agresiones contra los centros fenicios por parte de sus rivales en el comercio, los griegos, los cuales quisieron aprovecharse de ese momento de inestabilidad del que venimos hablando. Estas acciones fueron las que provocaron la intervención de Cartago, que se aupó como una especie de árbitro en las cuestiones políticas y económicas de los antiguos centros fenicios, que fueron quienes le requirieron en su defensa. Conocemos bien el dato de que gran parte de estas poblaciones no contaban con un contingente militar importante, ni les interesaba mantenerlo, pues sabían que podían contar, a la menor dificultad, con la ayuda de las tropas de Cartago, que se erigió como madre protectora de todos sus aliados. La implantación fenicia en Sicilia y Cerdeña fue completamente diferente lo que provocó también que el posterior dominio cartaginés de los territorios tuviese matices muy distintos (Gómez Bellard, 1991, 48 y ss.).

La presencia de los cartagineses en las islas en los largos periodos de paz que existieron entre todos los conflictos, supuso la aceleración de los procesos de aculturación. Durante estos lapsos de tiempo, la sociedad púnica adquirió influjos helenísticos que fueron claves para su evolución y desarrollo posterior y que veremos claramente reflejados en algunas manifestaciones culturales tales como la arquitectura. En Cerdeña, las causas de la penetración púnica fueron las mismas que las de la anterior presencia fenicia; la enorme riqueza de la isla en materias primas, especialmente hierro y plomo argentífero. También aquí las causas bélicas y el antagonismo entre púnicos y griegos supusieron la entrada y el posterior establecimiento de los cartagineses. La acción de los griegos no sólo ponía en peligro a las antiguas ciudades fenicias, sino que sobre todo, dificultaba el comercio a través de las rutas marítimas históricamente dominadas por los semitas.

El control púnico de la isla de Cerdeña fue absoluto, al contrario del que mantuvieron en el oeste de Sicilia. Para asegurar el control de la isla, levantaron fortificaciones y sistemas de control de territorio (Barreca ,1978, 126) donde se presentaron numerosos aspectos técnicos novedosos y adaptados, en mayor o menor medida, a los preexistentes de origen sardo-nurágico y fenicio arcaico. La presencia púnica en los diferentes lugares se manifestó con diferente intensidad. No podemos definir esta presencia como imperialista, como algunos investigadores aceptan. Tan sólo en el caso de Cerdeña, como se ha detallado arriba, el control político de los cartagineses fue más rotundo que en el resto de los territorios, pues se ocupó el espacio geográfico con contingentes militares y con población civil y además se explotó comercialmente. 
En el caso siciliota, los procesos de aculturación se dieron en las épocas de paz y su volumen fue tan amplio que se puede hablar de una sociedad púnica en Sicilia totalmente permeable a los influjos helénicos (Gómez Bellard, 1991, 50) lo que sobre todo incidió en el desarrollo de la arquitectura. En Sicilia, ya desde época fenicia arcaica, el interés de los semitas estuvo en el control de los puntos estratégicos y en la fundación de bases de apoyo para las rutas de navegación, lo que demuestra el enorme valor estratégico de esta gran isla del Mediterráneo Central.

Para el caso de la Península Ibérica, tan sólo podemos pensar en un interés imperialista cartaginés durante la etapa de control bárquida, en plena Segunda Guerra Púnica, en la que se fundaron nuevos centros urbanos, se realizaron aportes importantes de población, y se explotaron sistemáticamente los recursos naturales. De todas formas, para algunos (López Castro, 1991, 66) Cartago se erigió como protectora de los intereses comerciales de los fenicios occidentales desde el 510 a.C. cuando se reconoció en el Primer Tratado Romano-Cartaginés el monopolio comercial cartaginés en el Mediterráneo y ya principalmente desde el tratado del 348 a.C. cuando además del control comercial, se prohibió a los romanos y a sus aliados la fundación de colonias en el Extremo Occidente. En la Península, pues, será difícil admitir una política imperialista como la llevada a cabo en Cerdeña por los cartagineses, por lo que debemos pensar en una hegemonía política y económica de la ciudad norteafricana sobre las antiguas fundaciones fenicias.

De la expansión cartaginesa por el Mediterráneo surgió todo un conjunto de población caracterizada por el fenómeno del mestizaje, a la que sucesivamente se iban incorporando nuevos grupos humanos, procedentes del norte de África, con lo que se iba afianzando el elemento cultural púnico, con la arquitectura o la lengua como algunos de sus rasgos propios y diferenciadores.

Así pues, desde este momento comienza a generalizarse una cultura púnica por todo el Mediterráneo central y occidental. Se extiende tanto a través de nuevas fundaciones y ocupaciones de territorios poco poblados tales como el Levante de la Península Ibérica o la costa de Argelia, como también a través de la influencia directa sobre territorios de gran tradición cultural con establecimientos antiguos, bien de poblaciones indígenas, bien de colonos procedentes de oleadas migratorias del norte de África, o de la primera gran presencia comercial fenicia, desde el siglo VIII a.C. (casos del sur de la Península Ibérica, Ibiza, Cerdeña o Sicilia). En estos luga- res aparecerán, por ejemplo, modelos arquitectónicos que responden a un mismo patrón cultural, pese a la gran heterogeneidad manifiesta de las poblaciones púnicas de los distintos lugares del Mediterráneo, que tendrán peculiaridades propias de cada lugar en los que la tradición anterior tendrá gran influencia y por lo tanto persistirá en gran medida.

El cierre cronológico del proceso cultural protagonizado por la ciudad de Dido, es, curiosamente, bastante más difuso que el propio final "histórico" del mundo cartaginés, que desaparece tras la destrucción de la Megalópolis al final de la Tercera Guerra Púnica en el 146 a.C. Es ésta, sin duda, una fecha clave, que pone término a más de siete siglos de historia de una cultura eminentemente híbrida, con claros componentes orientales, pero que fueron matizados por el halo africano y occidental de los diferentes enclaves, que hicieron de esta cultura posiblemente la más mediterránea de todas las que se dieron a lo largo de la llamada Protohistoria del Mediterráneo, principalmente por la propia idiosincrasia de un pueblo que trató de aglutinar la erudición, el desarrollo y los conocimientos de dos mundos a ambos lados del mar (o lo que es lo mismo, del universo conocido en ese momento) sin perder nunca su identidad original.

Decimos que la fecha que supone el final de la cultura cartaginesa es difusa, porque no existe realmente esa fecha; no podemos afirmar que con la destrucción de la cuidad en el 146 a.C., se perdiese una cultura tan rica y arraigada. A pesar de la fuerza y el eminente poder de aculturación de Roma, los antiguos territorios dominados por Cartago mantuvieron vivas cuestiones de gran importancia como la lengua, las creencias y las manifestaciones religiosas. El arraigo y el conservadurismo cultural de las poblaciones púnicas era tal que aún a finales del siglo IV de nuestra era, San Agustín, obispo de Hipona, al querer evangelizar a campesinos del Sahel, no comprendía la lengua que éstos empleaban y, a su pregunta de "...pero, vosotros que sois" los campesinos contestaron en lengua púnica simplemente: "somos cananeos"

\section{Unde interrogati rustici nostri quid sint punice respon- dentes Chanaani}

\section{(S. Agustín. Epistola ad Romanos inchoata, Expositio 13)}

También en los lugares alejados del foco norteafricano, los influjos púnicos se dejaron sentir tanto en la arquitectura, como en otros aspectos de la cultura, incluso adentrados varios siglos en nuestra era. Buen ejemplo de ello son los casos 
del sur de la Península Ibérica (Bendala Galán, 1982, 193; López Castro, 1995) y de Cerdeña (Barreca, 1988, 49 y ss.) por citar los dos más significativos.

\section{BREVE APUNTE SOBRE LA HISTORIOGRAFÍA ClásiCA: DEL MENOSPRECIO A LA ALABANZA}

Pese a la imagen tradicional bárbara, sanguinaria y pérfida de la civilización cartaginesa, pese a los falsos tópicos asumidos históricamente como verdaderos, basados fundamentalmente en las parciales opiniones de los escritores latinos, que se encargaron de menospreciar a su enemigo histórico, Cartago se muestra hoy ante la historia como nexo cultural que se encargó de unir Oriente y Occidente, de estrechar la mano a diferentes pueblos y conformar una sólida base sobre la que se construyó una comunidad mediterránea, que no alcanzó, como es lógico, el desarrollo de la griega, pero que bien podría haberlo logrado de no verse truncadas sus aspiraciones por la aparición de un poderoso e invencible enemigo: Roma.

La cultura híbrida, la mezcla de elementos orientales semitas, griegos y beréberes generó una civilización rica, porque precisamente en la variedad y en el mestizaje está la riqueza. Si ya habíamos alabado la cultura fenicia como una sociedad que aglutinó tradiciones orientales ancestrales, la cartaginesa absorbió aquella, la asimiló y la fundió con las tradiciones preexistentes en el área líbica y con aquellas que fueron aprehendiendo en sus contactos más o menos violentos con los griegos de Sicilia. La historia de Cartago fue, durante siglos y siglos, la historia de un pueblo vencido, desconocido y bárbaro; una sucesión de acontecimientos históricos que demostraban que la perfidia, la traición y la falsedad no tenían cabida en un espacio "civilizado", dominado por la razón y el orden. A pesar de que personajes celebérrimos como Aristóteles alababan la igualdad y la valía democrática de la Constitución de Cartago, o aunque otros como Tácito afirmaran "Antequam Roma vicus esset, iam Karthago civitas erat" tratando de exaltar la mítica Cartago, vencida por Roma, para enaltecer aún más la magna obra llevada a cabo desde la Urbs, otros dedicaron todo su esfuerzo a contribuir a la dannatio memoriae más injusta, rota tan sólo por vocacionales historiadores de la talla de Plinio el Viejo y Tito Livio, que se movieron en la más completa ambigüedad ante los datos que lograron manejar.

$\mathrm{Si}$ atendemos a los datos que nos ofrece la lectura de las fuentes clásicas, el universo púnico se derrumbó per se, es decir, a causa de su propia naturaleza. En el fin de este pueblo vencido tenemos que añadir la ira de los dioses que castigó sin piedad por su crueldad manifiesta, por su propia personalidad despiadada. Esta imagen viene definida a través de siglos y siglos en los que los únicos datos que se han manejado han sido las referencias de las fuentes clásicas, a menudo pertenecientes a autores latinos como Polibio, Diodoro, Tito Livio y Apiano, que describieron al pueblo púnico desde la perspectiva del vencedor, desde la parcialidad que se manifiesta a través del que salió victorioso, que unas veces despreció por completo a su aniquilado enemigo y otras veces lo ensalzó para enaltecerse de esta manera a sí mismo.

\section{DE la EdAd Media Al SIGLO XIX: Co- LECCIONISMO, EXOTISMO, ROMANTICISMO Y ORIENTALISMO}

En la destrucción de Cartago en la primavera del 146 a.C. por las tropas comandadas por Escipión, debemos colocar el despegue económico y político de su antagónica potencia mediterránea, es decir, Roma, que se transformó en la gran dominadora y en la gran potencia hegemónica. Es ésta, sin duda, la principal causa por la que de Cartago nos quedó la imagen de un pueblo vencido, casi olvidado. Sin embargo será aquí, en el trasfondo romántico que implica una situación como la que tuvo que afrontar Cartago donde radica una de las principales causas del surgimiento de un especial interés en el conocimiento de esta cultura.

La historiografía durante la Edad Media es fácilmente criticable en su conjunto; al teocentrismo que inunda cualquiera de las historias relatadas en este periodo, hay que sumar la falta de sentido crítico y de rigor metodológico-científico. A lo largo de este periodo la Ciencia Histórica no se manifiesta como un estudio autónomo, y se ve inmersa dentro de las corrientes culturales "oficiales" tales como la Filosofía y la Teología (Ferrer Albelda, 1996, 17). En el caso de la historiografía de Cartago, ésta padece exactamente las mismas vicisitudes que cualquier otro de los acontecimientos históricos: se escribe la historia de las grandes batallas, de los grandes personajes y es ese precisamente el tema central de cualquiera de las fuentes medievales que de ésta cultura se ocupan.

La principal fuente de conocimiento nos la proporciona la obra de San Agustín, del siglo IV y la de su discípulo Orosio, quien redactó a principios del siglo V la obra Historia contra los paganos, donde el mundo cartaginés aparece como un agente negativo que esta abocado al fracaso por 
su propia idiosincrasia (Ferrer Albelda, 1996, 19). En estas obras se aprecia una especial animadversión por todo lo relacionado con Cartago, como ciudad pagana y enemiga no sólo de la fe, sino también del orden universal promovido desde Roma.

En época moderna no variaron demasiado muchos de los postulados historiográficos que se encargaron de escribir la historia de Cartago y sus territorios. La sombra de los textos clásicos griegos y romanos es lo suficientemente alargada como para cubrir cualquier intento de búsqueda de testimonios fieles sobre más de trescientos años de soberanía política y económica en el Mediterráneo central y occidental. De nuevo toman la cabeza los estudios sobre las Guerras Púnicas y la derrota de Cartago por parte de Roma. Pensemos que muchos de estos estudios fueron auspiciados por Carlos V, una figura que asumió su papel de Emperador a la perfección y que no sólo se colocó a la cabeza de los designios del mayor imperio europeo tras el Romano, sino que, alzándose como nuevo César, buscó en el antiguo poderío de Roma las raíces del nuevo orden europeo que él mismo promovió.

Los siglos XVII y XVIII ofrecen una historiografía de nuevo centrada en los grandes acontecimientos bélicos, en las grandes victorias y derrotas, en los grandes tratados y en los actos heroicos. Podemos afirmar, por lo tanto, que las recreaciones literarias y las fábulas redactadas en los últimos siglos crecen aún más en este periodo, añadiendo nuevas invenciones y recuperando otras, ya que se pierde la tradición de acudir a las fuentes clásicas de manera directa para centrarse en las lecturas de los textos medievales y modernos, con lo que se van acumulando errores.

La erudición ilustrada y el academicismo europeo del siglo XVIII se ocupó de rescribir la Historia, pero partiendo desde postulados centrados en la tradición y en la sucesión de acontecimientos recogidos en la Biblia, siempre que se fuese a tratar sobre el mundo prerromano. Pese a ello, durante este "Siglo de las Luces" sí se entiende la Historia como una Ciencia y se comienza a trabajar sobre la misma de una forma independiente. Esto provocó una crítica constructiva sobre las publicaciones existentes hasta el momento e incluso surgieron corrientes que abogaban por unos enfoques mucho más sociales y políticos, alejados de la sucesión de grandes personajes y grandes acontecimientos que habían protagonizado cualquiera de los textos elaborados hasta esa fecha. Parece que la historiografía ilustrada fue, fundamentalmente, antiheroica (Ferrer Albelda, 1996, 55).
La búsqueda de lo original y de los orígenes como única salida a una libertad insatisfecha y el alejamiento de una sociedad en constante decadencia llevó a muchos eruditos de las primeras décadas del siglo XIX a sumarse al Romanticismo, aunque fuese de una manera tardía. Estos intelectuales europeos se alejaron de la razón y del academicismo del siglo anterior para buscar nuevos mundos y descubrir otros lugares. Precisamente gracias a este movimiento se comenzó a redescubrir Cartago como centro de las nostalgias de muchos, que trataron de encontrar infinitos y lejanos países, en espacio y en tiempo. La búsqueda de lo expresivo, por encima de lo bello, y el rechazo a la perfección del arte clásico promovido por Winckelmann provocó un mayor interés en las culturas periféricas, alejadas de la tradición y del gusto oficial.

Las corrientes orientalistas que entroncaban directamente con el movimiento romántico de los primeros años del siglo XIX fueron las que promovieron los citados sentimientos de evasión y búsqueda de lo original. En ese momento el viaje por el norte de África se convirtió en uno de los destinos primordiales. Debemos incluir también el especial interés que muchos eruditos mostraron por la cultura púnica, principalmente por todo el halo oculto y mistérico que la rodeó. A muchos de los personajes cultos del viejo continente les atrajo lo primitivo y escatológico de la civilización cartaginesa, cuyo conocimiento adquirieron a través de la lectura de las fuentes clásicas. Muchos de estos personajes trataron de recuperar datos sobre la existencia de un pueblo que mantuvo su hegemonía durante siglos en el Mediterráneo, pero que tras ser derrotado por los romanos, quedó sumido en el más profundo de los olvidos. Veremos como todo el interés en la extracción de piezas de valor para colecciones privadas y en el especial morbo y afán de recuperar rasgos de este pueblo derrotado, atrajo a personajes adinerados y a literatos románticos de todo el vecino continente europeo.

Humanistas de todas las épocas se detuvieron siempre en las fuentes que aludían directamente al mundo cartaginés, quejándose a menudo de que ninguna fuese propiamente púnica y que siempre fuesen obra de manos de personajes procedentes de Grecia y Roma, los dos enemigos naturales de Cartago. Los textos que aluden al mundo púnico no sólo aparecen desde época moderna; ya desde la Edad Media existen referencias a monumentos y a vestigios de época púnica en la fructífera provincia islámica de Ifriqiya. De los escasos restos púnicos conservados hacen alusión algunos textos árabes que mencionan la destrucción intencionada de gran 
parte de éstos que se ubicaban en zonas costeras, para evitar que fuesen ocupados por los cruzados cristianos. Se tiene conocimiento de cómo las autoridades árabes tras expulsar a los cruzados en 1270, ordenaron arrasar todos los restos monumentales antiguos hasta el nivel de las cimentaciones para que no les sirviesen en futuras invasiones (Prados Martínez, 2000, 303).

En la mente de los primeros aventureros que desde las últimas décadas del siglo XVIII iniciaron el viaje a Barbaria (Nombre romántico que alude a las provincias del Africa Romana, que fueron ocupadas anteriormente por el Imperio Cartaginés) estuvo siempre el interés de recuperar Cartago con toda su fuerza y su originalidad, que hizo de ella una cultura mixta ubicada entre Oriente y Occidente, que jamás ocultó su tradición norteafricana. Estos primeros personajes quedaban impresionados de la majestuosidad de los vestigios que se veían íntegros en Tunicia, aunque todos ellos, sobre todo aquellos particularmente monumentales, se fechaban en época romana.

Quizás esta situación en la que se encontraba esta cultura hizo acrecentar aún más si cabe la leyenda y el interés de viajeros y científicos europeos. Al tiempo que las campañas napoleónicas se centraban en extraer antigüedades en Egipto, otros personajes como el vizconde de Chateaubriand (1768-1848) gran conocedor de países africanos y asiáticos, se vanagloriaban de ser los primeros en haber descubierto por ejemplo la auténtica ubicación de los puertos de Cartago, la sede de la gran flota que le dio el nombre a la ciudad de "reina de los mares", aunque en general, salieron tremendamente decepcionados de los escasos y poco monumentales restos de época cartaginesa que lograron identificar. Las crónicas del viaje del afamado vizconde francés se recogen en un manuscrito en el que explica el

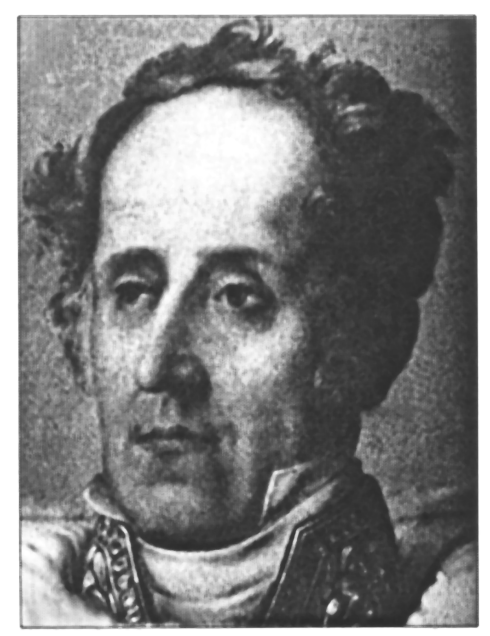

Retrato de René de Chateubriand

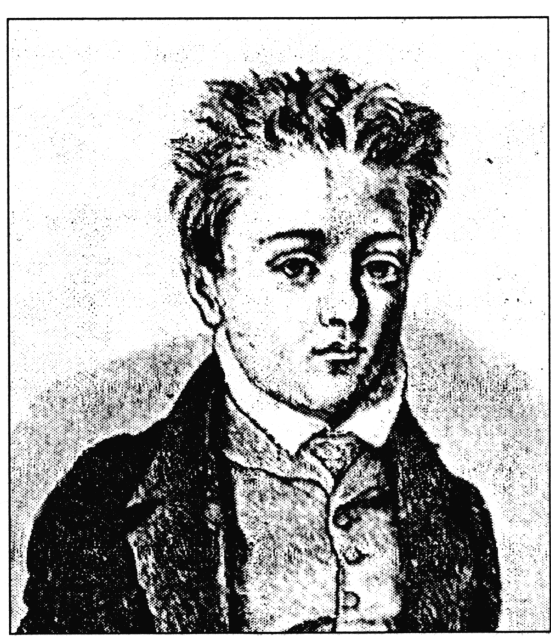

Grabado de Flaubert en su juventud

interés cultural de su viaje por el Mediterráneo, que comenzó en Tierra Santa, pasando por Grecia, para llegar finalmente a Cartago, en 1807.

A todo este conjunto de vicisitudes históricas por las que pasó la Cartago Púnica, que provocaron la pérdida de memoria histórica sobre ella, y a la enorme escasez de restos hay que sumar que la ciudad norteafricana se convirtió durante siglos en la cantera de toda la región. De las ilustres piedras de Cartago surgieron nuevas ciudades como Túnez o Kairouan, además de gran parte del mármol empleado en la edificación de la catedral de Pisa.

Vistos estos antecedentes, no es sorprendente pues que los principales datos sobre el mundo púnico hayan sido obtenidos años después con la llegada de las intervenciones arqueológicas por medio de excavaciones, donde se han encontrado vestigios importantes de esta civilización que eran imposibles de admirar. Muy probablemente todo este problema del escaso interés que suscitó el mundo púnico hasta bien entrado el siglo XIX tiene su origen en estas cuestiones de la escasez de vestigios de carácter monumental del orden de los conservados en Italia, Grecia o Egipto que provocaron el interés de las principales naciones europeas que realizaron enormes desembolsos económicos para recuperar el mayor número posible de antigüedades.

La figura de Gustave Flaubert (1821-1880) el celebérrimo autor de Madame Bovary, destaca en este momento. El definido por los especialistas de la literatura como precursor del realismo en la novela viajó por el norte de África especialmente fascinado con todo lo relacionado con la Cartago mítica, de ahí obtuvo la inspiración necesaria para la creación de su novela Salammbô (1862) 


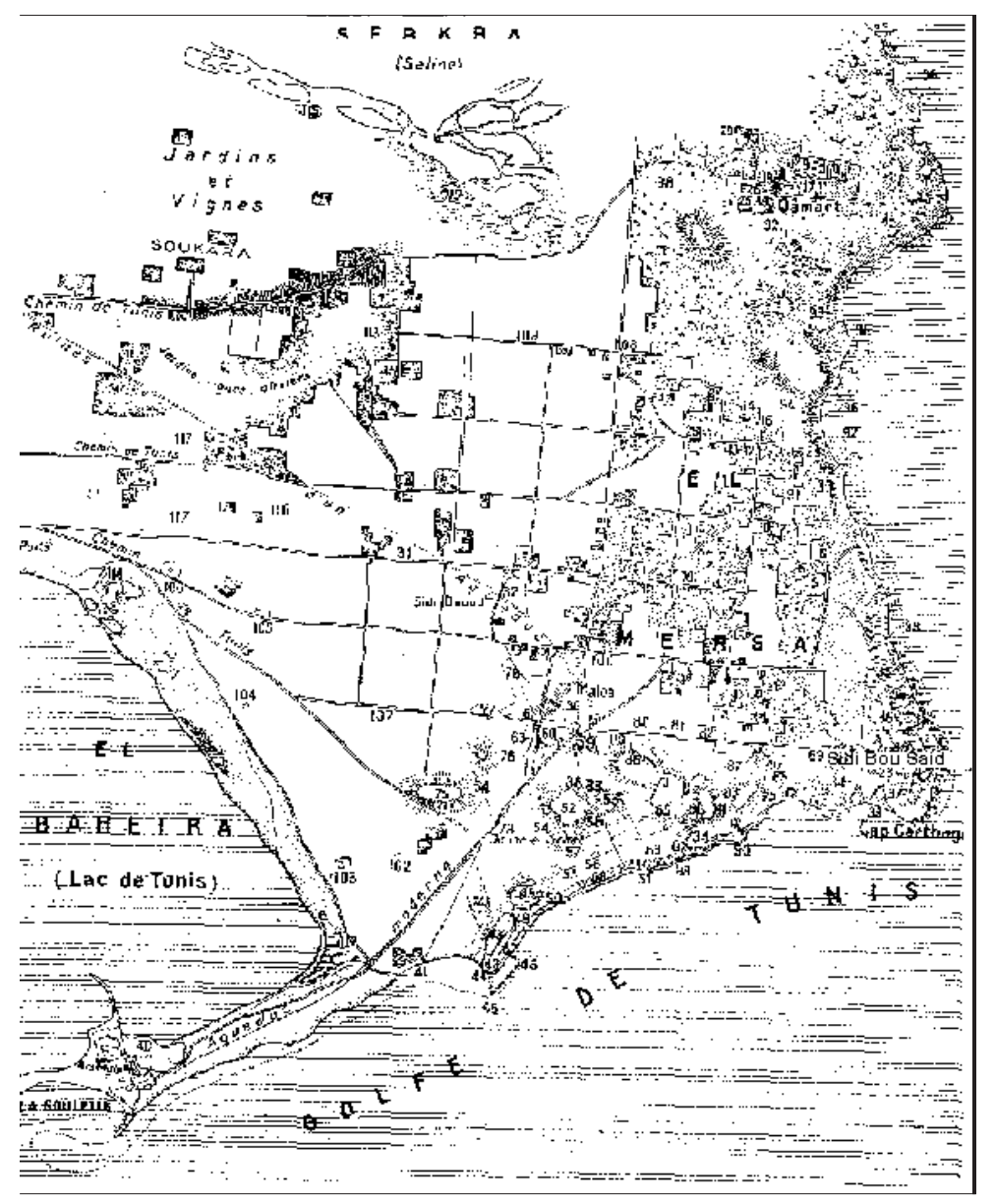

Mapa topográfico de Cartago elaborado por Falbe (1833).

que supuso una magnífica, imaginativa e ilustrada evocación de la vida cartaginesa. En los periplos que por el norte de África llevó a cabo Flaubert desde 1858, jamás encontró una arquitectura púnica interesante, es más, incluso llegó a escribir que "no existe la arquitectura púnica", aunque por el contrario quedó maravillado por los santuarios, los tofets y las necrópolis que pudo llegar a contemplar y que tuvieron una vital implicación en la elaboración de su Salammbô. La novela, incluida dentro de la corriente orientalista por los especialistas, no obtuvo una gran aceptación, aunque despertó en los ambientes cultos franceses un especial interés por la historia de Cartago. La antigua metrópolis púnica fue a menudo citada en obra epistolar "Correspondance" que conforman una de las producciones literarias más interesantes del autor galo.

\section{Los INICIOS DE LA Historiografía PÚNICA: DEL POSITIVISMO CIENTÍFICO A LOS INICIOS DE LA DISCIPLINA ARQUEOLÓGICA.}

El primer trabajo arqueológico como tal fue realizado sobre la ciudad de Cartago en 1833 por el cónsul general de Dinamarca en Túnez, C.T. Falbe, el cual se preocupó de recuperar datos tanto desde el punto de vista cartográfico como desde el trabajo de campo realizado directamente sobre el terreno. Así pues, el equipo dirigido por este político levantó el primer mapa topográfico de la ciudad de Cartago (Falbe, 1833). Para el magnífico trabajo que realizó, se apoyó en la ubicación de más de un centenar de puntos de interés enmarcando las improntas que formaban el terreno en cuadrados de 2.400 pies de anchura (exactamente las superficies estipuladas en el catastro ordenado por los Graco en el 122 a.C.).

Desde este primer trabajo puramente científico, las iniciativas sobre el conocimiento de la ciudad de Cartago se multiplicaron. En 1837, se organizó la Sociedad para la Exploración de Cartago, con Falbe como uno de los miembros más destacados. Entre los estatutos de esta sociedad se incluían una serie de puntos que eran justificables en su momento, pero hoy del todo deleznables. Estos puntos permitían la venta de objetos de la excavación a particulares o a museos extranjeros a cambio de lograr financiación 
para las excavaciones. La interpretación de los restos exhumados reflejaban un claro Positivismo así como la motivación en la escogida de los diferentes lugares objeto de excavación (centrados en encontrar los suntuosos palacios imaginados por Flaubert).

El pastor anglicano Nathan Davis exploró todo el litoral de Cartago, y apoyándose en los estatutos de la Sociedad, enriqueció en gran medida el British Museum con mosaicos romanos y con otros muchos objetos provenientes de sus excavaciones. Este "arqueólogo" y explorador inglés, amigo de Flaubert, se centró en la parte baja de la ciudad y publicó todos los resultados de sus investigaciones en 1861 (Davis, 1861).

Otro de los pioneros que realizaron investigaciones arqueológicas en el territorio tunecino fue Charles Ernest Beulé. Este miembro del Instituto Francés comenzó sus trabajos en 1859 tras haber leído a Flaubert y por lo tanto, tras ser atraído por lo sugestivo, oculto y fascinante de la cultura púnica. Tanta fue la impresión que la novela de su compatriota le causó, que se empleó a fondo para tratar de hallar los restos del palacio de la reina Dido, que incluso llegó a ubicar sobre un dibujo de la planicie existente en la zona superior de la colina de Byrsa.

A medio camino entre lo real y lo imaginario, la cultura púnica comenzaba a salir a flote; poco a poco se comenzaban a detener un mayor número de especialistas en este mundo que tan sólo hacía unos lustros, había comenzado a ver la luz de nuevo, tras siglos de oscuridad. Se trata del redescubrimiento de la cultura púnica, en el que tomaron parte una sucesión de personajes que exhumaron datos ocultos bajo siglos de sedimentos (no sólo geológicos, sino también intelectuales) con unas metodologías y un cientifismo fácilmente criticables desde los avances que disfrutamos y los trabajos que desarrollamos hoy en día.

El primer gran hallazgo de materiales púnicos fue le exhumación de más de dos mil estelas pertenecientes al tofet que recuperó E. de Sainte Marie, un miembro del consulado francés en Túnez, con escasa formación arqueológica, que tuvo la suerte que no había tenido Beulé, pues este hallazgo apareció unos metros por debajo de donde había dejado la excavación aquel. La mayor parte del conjunto de las estelas fueron perdidas durante el naufragio del buque que las trasladaba hacia Francia.

Desde aquí y hasta finales del siglo XIX y principios del $\mathrm{XX}$, tenemos el inicio de la arqueología púnica como una disciplina científica, dotada de un método, más o menos correcto en los primeros años de su existencia. El interés ya no sólo provenía de las autoridades europeas, sino también de las tunecinas, lo que sin duda facilitó la realización de grandes empresas arqueológicas para la recuperación del mayor número posible de restos. Desde 1882 Túnez pasaba a formar parte del Protectorado Francés, lo que provocó la llegada de estudiosos y eruditos desde este país, además de la creación de una reglamentación legal sobre las excavaciones y la conservación de antigüedades (decretos del 26 de Septiembre de 1890 y del 2 de Agosto de 1896). También el interés que el arzobispo de Argel, el padre Lavigerie, puso en las antigüedades púnicas supuso un gran desarrollo de las intervenciones, la mayoría de las cuales fueron llevadas a cabo por una orden de misioneros franceses, los "Pères Blancs", cuyo papel principal consistía en escolarizar a la mayor parte de los jóvenes tunecinos, y que se ocuparon de desarrollar un gran conjunto de intervenciones arqueológicas.

De entre todos estos Padres Blancos, destacó por encima del resto la figura de A. L. Delattre, un misionero llegado a Túnez en 1875 y que provenía del continente americano. Conjuntamente, el inicio del protectorado galo en el país norteafricano provocó un mayor control sobre los restos arqueológicos, que tuvo como mayor exponente la formación de un Servicio de Antigüedades. Durante estos años, la labor del Reverendo Padre Delattre fue incansable. Sus trabajos, los primeros de carácter sistemático, se extendieron a lo largo de más de cincuenta años y se centraron fundamentalmente en las necrópolis. El hecho de que fuesen las ciudades de los muertos los yacimientos que suscitaron mayor interés se explica porque eran éstos los lugares que ofertaban unos materiales más ricos y llamativos. Los trabajos de Delattre y de todo el equipo de los Padres Blancos, auspiciados por la Académie des Inscriptions et Belles-Lettres de París conformaron las primeras investigaciones científicas. Dichos religiosos fueron artífices de numerosos trabajos arqueológicos y epigráficos sobre el mundo púnico, que además publicaron en la colección "Publications des Pères Blancs", una de las pioneras en lo referente al mundo de la arqueología cartaginesa Las publicaciones de estos folletos, de entre 10 y 50 páginas, constaban de magníficas ilustraciones de las piezas, así como de excelentes fotografías. Todos ellos se incluían en una serie editada por el Museo Lavigerie de Saint-Louis de Carthage, desde 1897.

Todo pese a la utilización continua del método de "excavación" llamado Decauville, que consistía en el vaciado continuo de los hipogeos, 


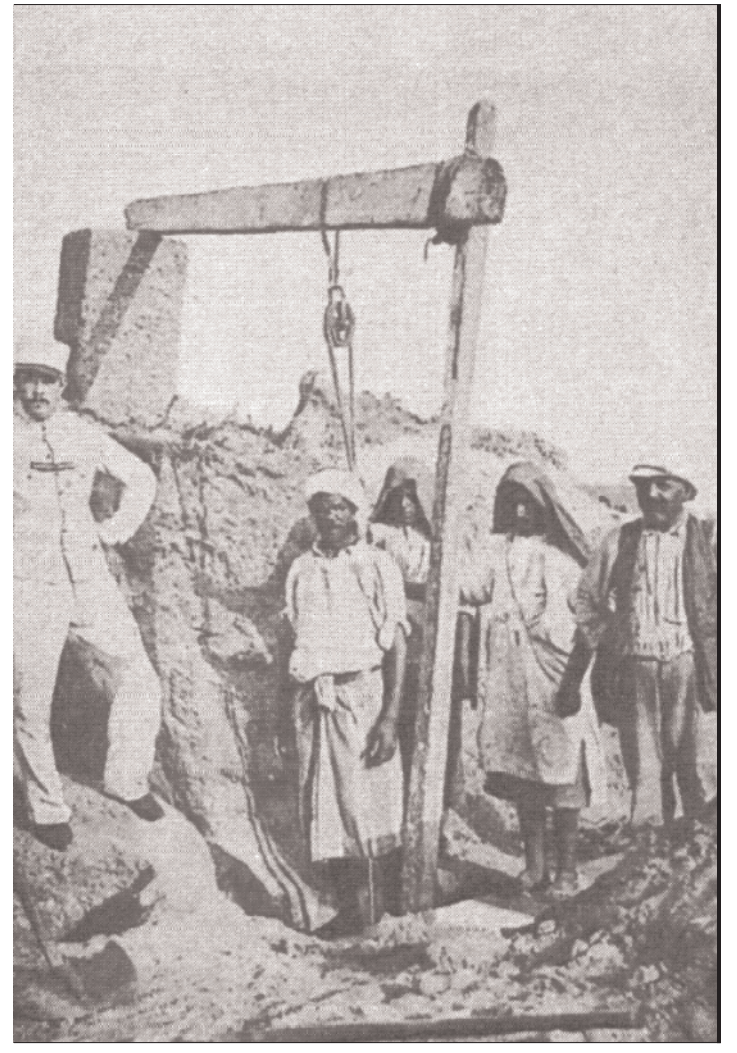

Excavaciones del R. P. Delattre en Cartago (1905)

practicando cortes verticales llenando unas vagonetas cuyos raíles de vía estrecha alcanzaban la puerta de las cámaras funerarias. Estas vagonetas eran volcadas después para cribar toda la arena, en unas labores más propias de buscadores de tesoros que de arqueólogos. Evidentemente ante estos métodos, era imposible contemplar una sucesión de deposiciones estratigráficas, por lo que la pérdida de datos era ingente. Para algunos, como G. Ville (Ville, 1968, 6), el Padre Delattre fue "el más célebre excavador y masacrador de la ciudad antigua de Cartago", fundamentalmente por los métodos que utilizó y por el volumen de tumbas que excavó. El enorme ritmo de excavaciones que se llevaron a cabo entre los años 1878 y 1903 se debió principalmente a la actuación de dos equipos, uno el de los Padres Blancos y el otro el del Servicio de Antigüedades. Ambos equipos trabajaron con gran precipitación como si compitiesen por obtener objetos cada vez más hermosos y valiosos. Las primeras prospecciones las llevaron a cabo los Padres Blancos en 1878 dirigidos por Delattre en la colina de Junon, dos años después continuó sus trabajos en la colina de Byrsa. Entre 1892 y 1906 excavó centenares de tumbas en Douimes, Bordj Jadid y en toda la planicie de Sainte Monique. Entre 1899 y 1901 más de 1.300 tumbas fueron vaciadas a menudo con una motiva- ción mayor en la búsqueda de objetos de valor que con un interés científico.

Desde 1899, P. Gauckler, el segundo director del Servicio de Antigüedades, tomó parte en numerosas excavaciones en Dermech, junto a las Termas de Antonino, donde se realizaron numerosas trincheras paralelas al litoral. La gran rapidez con la que se acometieron estas excavaciones llama bastante la atención. Los propietarios de los terrenos eran particulares que los alquilaban anualmente. Además como no había tiempo ni dinero, se puede contemplar al revisar las anotaciones realizadas durante estas excavaciones, como todo se basaba en un trabajo puramente mecánico, prácticamente en cadena. Se sabe por ejemplo que en 1900, P. Gaukler llevaba un ritmo de excavación de una tumba al día, e incluso en alguna jornada se llegaron a exhumar por completo dos o tres tumbas. De la lectura de los diarios se desprende que, en jornadas como la del 13 de Marzo de 1900, se abrieron las tumbas 223, 224 y 225, mientras que al otro lado de la colina, el equipo dirigido por el Padre Delattre llevaba aproximadamente la misma cadencia, como si de una carrera de fondo se tratara.

Las labores del Servicio de Arqueología fueron continuadas desde 1906 por A. Merlin, el nuevo director que suplió a Gauckler en el cargo, y por L. Drappier. Tan sólo el magnífico trabajo de Hélène Benichou Safar en 1982 ha podido poner en orden gran parte de toda la información que se extrajo durante todo este primera fase arqueológica, escasamente metódica pero sí al menos rigurosa en cuanto al registro de los hallazgos (Benichou-Safar, 1982).

Dentro de todo este conjunto de trabajos pioneros no podemos dejar de citar también a otros arqueólogos que centraron sus trabajos en estos momentos en el mundo cartaginés, así pues tenemos que mencionar a S. Reinach, E. Babelon (desde 1880) y sobre todo a F. Icard y a P. Gielly, que desde 1922 comenzaron las labores arqueológicas en la zona del tofet. Otros personajes se acercaron a las antigüedades siendo ingenieros o simples aficionados, propietarios de tierras en las que se habían encontrado de forma casual restos de época cartaginesa.

Como hemos visto, la mayoría de los primeros trabajos que se acometieron en el último tercio del siglo XIX se ocuparon de las necrópolis, lo que evidencia el interés que se tenía en la obtención de materiales en buen estado de conservación además de la recuperación de joyas y amuletos, piezas éstas de gran interés en subastas y museos. La Arqueología Púnica tardaría algunos 
años más en afrontar la problemática de la cerámica y sobre todo, en todo aquello relacionado con el campo del urbanismo y la arquitectura, lo que a priori parecía menos llamativo, que obtuvo un mayor desarrollo fuera de Túnez, de la mano de arqueólogos británicos e italianos que actuaron fundamentalmente en Sicilia y Cerdeña.

En el caso de la Península Ibérica, las primeras intervenciones arqueológicas llevadas a cabo en un yacimiento identificado como púnico fueron las de la antigua ciudad de Baria (Villaricos, Almería) dirigidas por el ingeniero de minas belga Louis Siret en el año 1890 y publicadas algunos años más tarde (Siret, 1908).

\section{La Arqueología Púnica. Desarrollo CRONOLÓGICO-HISTÓRICO A LO LARGO DEL SIGLO XX}

La Arqueología Púnica a lo largo del siglo pasado ha sufrido numerosos cambios de rumbo, pero si de todos ellos hemos de quedarnos con alguno, más allá de la evolución de los estudios y las tendencias historiográficas, es con el que marca el final del colonialismo y la presencia europea en los territorios norteafricanos. El final de los protectorados españoles y franceses fundamentalmente, e italianos e ingleses en una menor escala, trajo consigo un nuevo orden en la formación y el desarrollo de las investigaciones en los yacimientos de la órbita púnica. Tampoco podemos dejar de lado los dos enormes parones padecidos en el curso de las dos grandes guerras. Pero como no queremos plantarnos en tan cruentos acontecimientos para la humanidad y, por consiguiente, para la Arqueología, vamos a centrarnos en las transformaciones acaecidas tras el primer de los momentos mencionado, el fin del colonialismo, y en la evolución de las corrientes historiográficas que se han detenido con mayor o menor incidencia en la cultura púnica.

Partiendo de unas primeras décadas de claro continuismo en las intervenciones, desarrolladas bajo los auspicios de las naciones coloniales y tras el lapso de las dos guerras mundiales y el periodo de entreguerras, se pasó, en la segunda mitad el siglo a unas nuevas fórmulas de estudios de conjunto realizados entre los centros de investigación estatales de algunos de los países mediterráneos. Cabe destacar las labores desarrolladas desde los años cincuenta por el CNRS francés (Centre National de la Recherche Scientifique) y el CNR italiano (Consiglio Nazionale delle Ricerche).

Desde el punto de vista de la evolución del pensamiento, no podemos olvidar la creciente tendencia antisemita desarrollada en los países europeos, especialmente en aquellos de mayor presencia fascista, que tuvo una gran incidencia en el descenso del interés de las investigaciones de éstos países en su pasado fenicio y púnico. Curiosamente se aprecia un decrecimiento de este tipo de estudio en Tesis Doctorales directamente proporcional al crecimiento de trabajos dedicados a las grandes culturas nacionales y a la presencia de pueblos célticos en esos mismos territorios.

Las dos primeras décadas del siglo XX no aportaron en su conjunto grandes novedades. Tan sólo algunos trabajos en España como los de Pelayo Quintero Atauri en las necrópolis de Cádiz, o los de Whitaker en Mozia (Sicilia) estudiaban restos de entidad pertenecientes a época púnica. Las décadas de los cuarenta y los cincuenta no presentaron demasiadas novedades ya que la presencia griega era el factor dominante. El influjo etnocéntrico griego de investigadores de la talla de Schulten era bastante potente y tan sólo algunos autores como Bonsor, Cabré (éstos en las primeras décadas del siglo XX, antes de la Guerra Civil) Tarradell o García y Bellido valoraban la presencia fenicia y cartaginesa en los territorios por encima de la mayoría de colegas que habían sobrestimado la colonización griega (Tarradell 1951; 1960).

En los años sesenta y setenta el desarrollo de las investigaciones en yacimientos señeros italianos como Tharros y Mozia y los hallazgos casuales en suelo hispano de El Carambolo (Sevilla) y la Necrópolis Laurita (Almuñécar, Granada) aumentaron el interés. La década de los setenta del siglo XX fue bastante propicia para la arqueología púnica en el territorio originario norteafricano. A comienzos de ésta década se pusieron en marcha los proyectos de investigación internacionales cofinanciados por la UNESCO en Cartago. De estos proyectos destacan los angloamericanos en la zona de los antiguos puertos de la ciudad (dirigidos por el profesor H.R. Hurst) y los franceses en la Colina de Byrsa, la antigua acrópolis de la Megalópolis púnica (dirigidos por el profesor S. Lancel). También en estas fechas, y prácticamente con carácter anual, se iniciaron los Seminarios Internacionales de Kerkouane, dirigidos por el Profesor M.H. Fantar del Instituto Tunecino de Patrimonio, una fórmula bastante acertada de congregar en torno a un importante yacimiento a jóvenes investigadores y a consagrados estudiosos, algo similar a lo que se realiza anualmente en nuestro país en Ampurias y recientemente en Baelo Claudia; no sólo de cara a excavar en algunos sectores, sino también de cara a discutir sobre el terreno algunos de los problemas más importantes que plantean los restos y los materiales exhumados. 


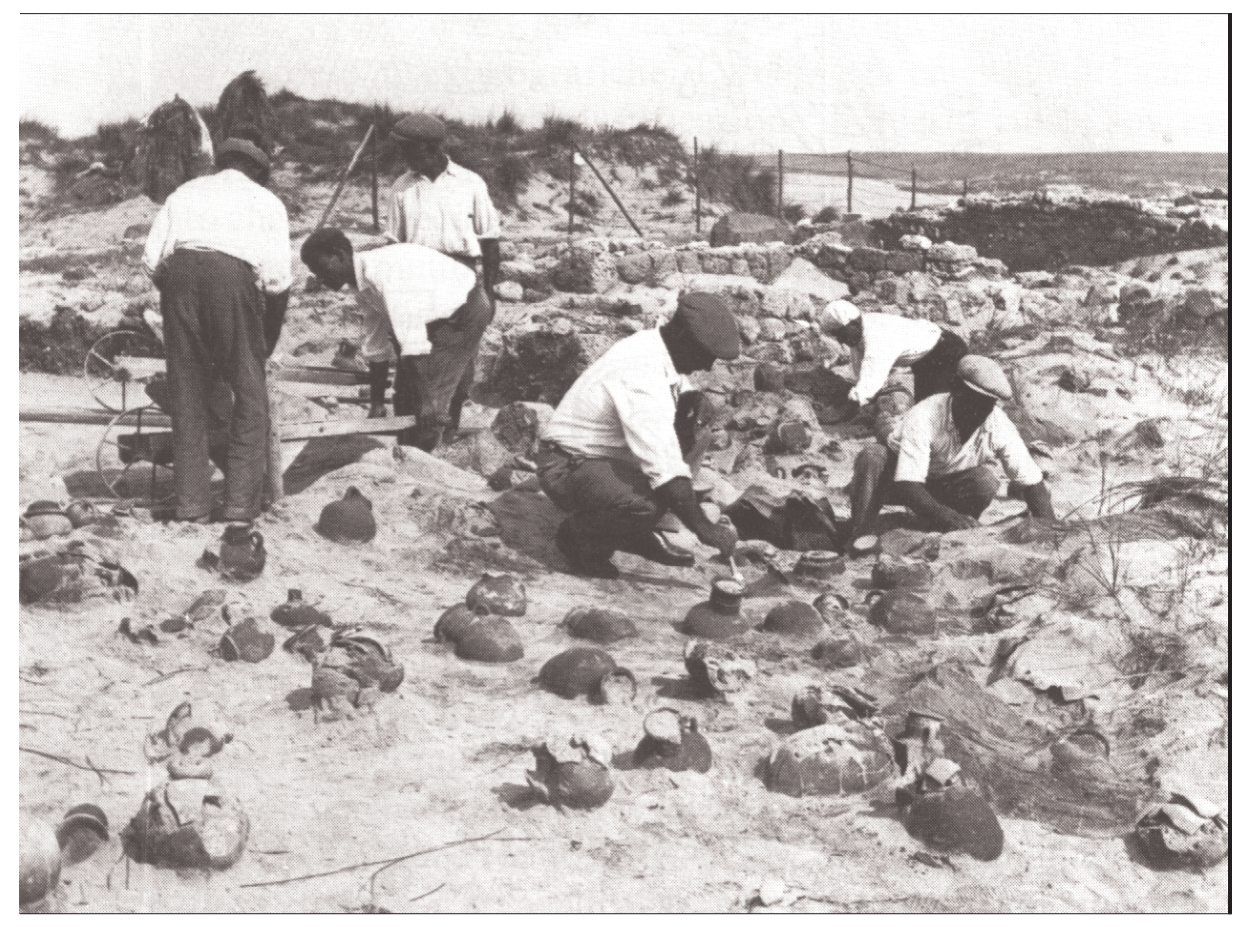

Excavación del tofet de Tharros (1961)

\section{Valoración CRÍtica: RUMbo a UN FUTURO INCIERTO}

En los últimos años, principalmente desde la celebración, a finales de los años setenta y principios de los ochenta, de los primeros congresos internacionales sobre el mundo fenicio y púnico, bajo los auspicios del Istituto per la Civiltà Fenicia e Punica y de su fundador, el malogrado profesor Sabatino Moscati, esta disciplina ha adquirido una gran relevancia en algunos de los centros universitarios y de investigación más importantes de la cuenca mediterránea.

Podemos afirmar sin pudor alguno que se trata en la actualidad de una de las disciplinas que se encuentran en pleno auge y desarrollo. Por primera vez equipos interdisciplinares compuestos por arqueólogos, historiadores y filólogos componen los proyectos de investigación y publican -con desigual frecuencia, eso sí- los resultados de sus investigaciones en monografías exquisitamente elaboradas en la mayoría de los casos. Todo esto parece presagiar un maravilloso futuro a los estudios fenicios y púnicos, pero, esto no es del todo cierto, principalmente porque se trata de proyectos de investigación demasiado localistas y puntuales y, por toda la experiencia adquirida en los últimos ciento cincuenta años y que acabamos de tratar de resumir en estas líneas, sabemos que esta disciplina necesita de estudios de conjunto, coordinados entre varias instituciones y apoyados por diferentes gobiernos.
Algo similar a lo que se empezó a realizar con las misiones francesas, americanas, británicas y danesas en Cartago en la década de los setenta del pasado siglo, pero desde unas motivaciones ordenadas, coordinadas, con unos medios y unos objetivos comunes y, como no, organizadas, dirigidas y sancionadas por el gobierno tunecino.

Precisamente la existencia de proyectos de investigación financiados por distintas instituciones, sean públicas o privadas, pero no coordinadas entre sí, provocan la diversificación de los datos $y$, en muchos casos, el desconocimiento, por gran parte de la comunidad científica interesada, de los resultados de muchas de las intervenciones arqueológicas y de los estudios realizados. Desde luego en plena era de las telecomunicaciones y de Internet, es prácticamente un delito no poner en común y contrastar los datos, teniendo en cuenta, que, por desgracia, muchos de ellos vienen ofrecidos a través de excavaciones arqueológicas de urgencia efectuadas en los cascos históricos de las urbes que fueron antiguos centros púnicos (pensemos por ejemplo en los casos de Cádiz, Málaga, Marsala, Palermo o Cagliari, por citar algunos de los más importantes).

Como adelantó hace unos años el profesor Ruiz Mata, es complicado y bastante presuntuoso programar en forma alguna lo que deben ser los objetivos principales de la investigación en un futuro a corto y medio plazo (Ruiz Mata, 1998, 435) pero, pese a ello, sí podemos desde aquí abogar por la realización de proyectos interdisci- 


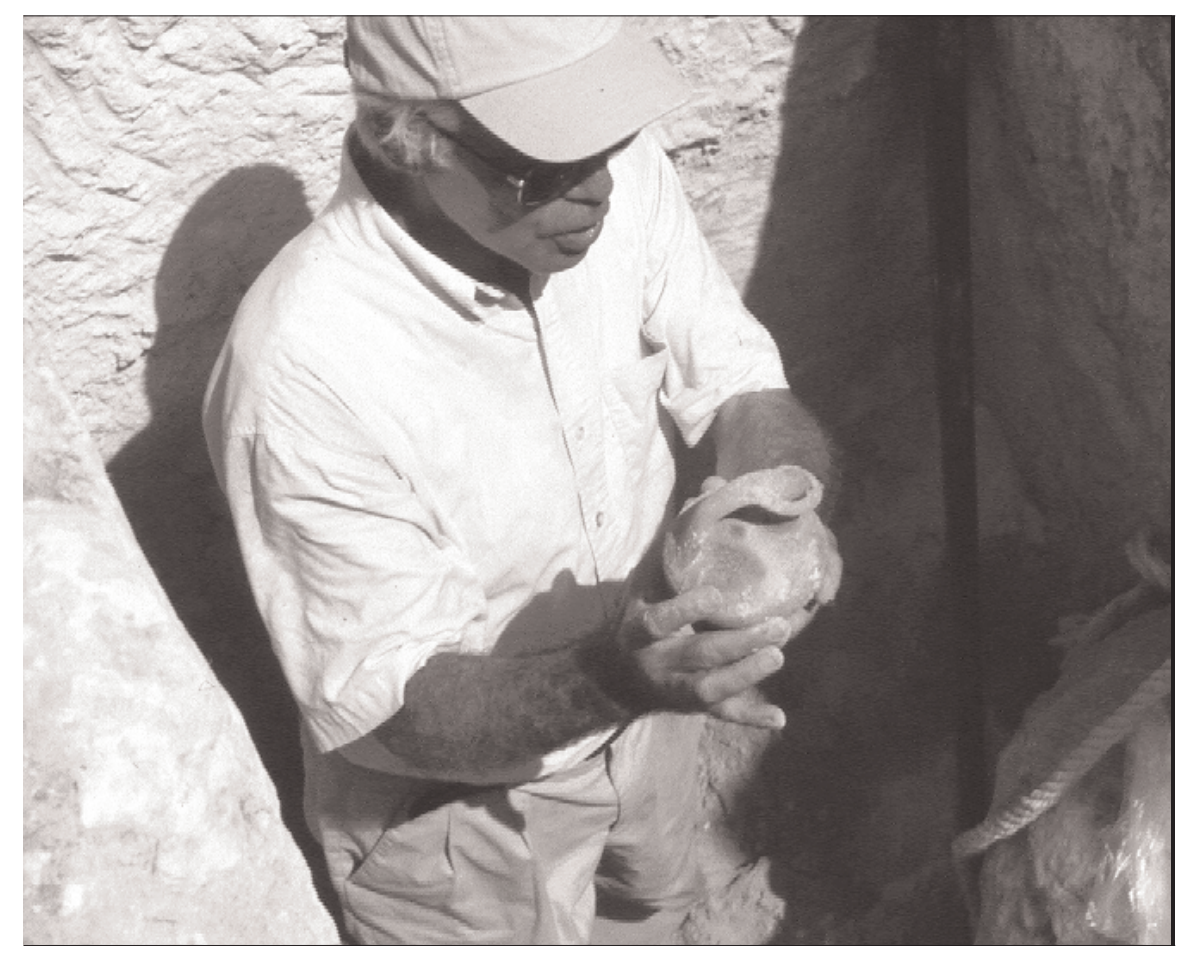

Mohamed Fantar en Arg-el Ghazzouani (Agosto de 1999)

plinares que se centren, al menos en un primer peldaño, en los estudios de territorio, aplicando las nuevas fórmulas y las nuevas teorías, para, con posterioridad, llevar a cabo excavaciones sistemáticas en los yacimientos centradas también, en una primera fase, en intervenciones estratigráficas en los lugares que presenten los principales problemas. Sólo en una fase posterior a ésta, y una vez conocidos los resultados de sondeos y analíticas, se deberían realizar intervenciones en extensión de cara a obtener análisis más detallados del urbanismo y de la arquitectura en conjunto, con buenos programas de conservación, restauración y puesta en valor para divulgar e incluir los asentamientos púnicos más representativos dentro de los principales circuitos culturales. No queremos pasar por alto la labor que, en este mismo sentido y con similares motivaciones, realiza un equipo de la Universidad Autónoma de Madrid en la ciudad púnica, romana y medieval de Carteia (San Roque, Cádiz) desde 1994 (Roldán Gómez, Bendala Galán, Blánquez Pérez y Martínez Lillo, 1998, 245 y ss.)

Dado que por el momento es impensable la realización de estudios cofinanciados por diversas instituciones públicas y privadas y por gobiernos de diferentes países, y que, tal y como se presentan en la actualidad las intervenciones arqueológicas, que dependen en muchos casos del presupuesto de la constructora de turno, del plazo de ejecución de la obra que sea y de la habilidad y capacidad gestora, más que de la valía científica, del arqueólogo titular, podemos afirmar que se cierne un futuro bastante incierto sobre el conocimiento de una cultura híbrida, que se manifestó en ámbitos dispares y de la que cada vez es más difícil poner en común muchos de los aspectos. Parece que tan sólo la utopía de establecer convenios de estudios y proyectos dirigidos desde una institución como la UNES$\mathrm{CO}$, a través de una política de nombramiento de algunos de los centros más importantes como Patrimonio del Mediterráneo, podría cambiar el rumbo al devenir científico. Utopía, sin duda, la de unir ambas orillas de un mar común que no sólo mantienen alejadas algunas millas marinas, sino el peso de la política y los intereses económicos y geoestratégicos que separan cada vez más, como brazos hercúleos, las tierras a uno y otro lado del Mediterráneo. Curioso símil, Hércules abrió la tierra y conectó los mares para beneficiar a los hombres, para permitir el paso de la cultura, de la civilización; hoy aprovechamos esa distancia para volver la cara a la historia y marcar unas diferencias antaño inexistentes.

\section{Bibliografía}

ACQUARO, E. (1978): Cartagine. Un impero sul Mediterraneo. Roma.

Almagro Basch, M. (1958): Origen y formación del pueblo hispano. Barcelona. 


\section{Almagro Gorbea, $\mathrm{M}^{\mathrm{a}}$. J.}

- 1984: La necrópolis de Baria. Excavaciones Arqueológicas en España $n^{0}$ 129. Madrid.

- 1986: "Excavaciones en la necrópolis púnica de Villaricos". Homenaje a Luis Siret, Cuevas del Almanzora 1984. Sevilla; pp. 625-637.

Astruc, M. (1951): La necrópolis de Villaricos. Madrid.

Babelon, E. (1896): Carthage. París.

Barreca, F.(1986): La civiltà fenicio-punica in Sardegna. Sassari.

Beltrán, A. (1952): "De Arqueología púnica”. Archivo Español de Arqueología XXV. Madrid; pp. 362-366.

Bendala Galán, M.:

- 1982: "La perduración púnica en los tiempos romanos: el caso de Carmo" Huelva Arqueológica 6 Primeras Jornadas Arqueológicas sobre Colonizaciones Orientales. Huelva; pp. 193-203.

- 1987: "Los Cartagineses en España". Historia General de España y América, Tomo I.2, Madrid; pp. 115-170.

- 1992: "El mundo feniciopúnico y su expansión mediterránea". Prehistòria de les Illes de la Mediterrània Occidental (X Jornades d'Estudis Històrics Locals). Palma de Mallorca; pp. 375-391.

- 1994: "El influjo Cartaginés en el interior de Andalucía". Cartago, Gadir, Ebusus y la influencia Púnica en los Territorios Hispanos. VIII Jornadas de Arqueología Fenicio-Púnica (Ibiza 1993). Ibiza; pp. 59-74.

- 2000: Tartesios, iberos y celtas. Pueblos, culturas y colonizadores de la Hispania antigua. Madrid.

Bendala Galán, M. y Navarro, J. (1991): "La colonización feniciopúnica". Boletín de la Asociación de Amigos de la Arqueología, XXX-XXI. Madrid; pp. 111-121.

Benichou-SAFAR, H. (1982): Les tombes puniques de Carthage. Topographie, structures, inscriptions et rites funéraires. París.

Beulé, C.E. (1861): Fouilles à Carthage. París.

BlázQuez MarTínez, J.M ${ }^{\mathrm{a}}$.

- 1975: Tartessos y los orígenes de la colonización fenicia en Occidente. Salamanca.

- 1980: "Colonización Cartaginesa". Historia de España I: Protohistoria. Madrid.

Cabré Aguiló, J.

- 1920a: "La Necrópolis de Tutugi: Objetos exóticos de influencia oriental en las necrópolis turdetanas". Boletín de la Sociedad Española de Excursionistas $n^{0} 28$. Madrid; pp. 1-44.

- 1920b: "Arquitectura Hispánica. El Sepulcro de Toya”.
Archivo Español de Arte y Arqueología I. Madrid; pp. 73-101.

Carcopino, J. (1943): Le Maroc antique. París.

CARTOn, L. (1929): Sanctuaire punique découvert à Carthage. París.

CinTAS, P.

- 1949: "Fouilles puniques à Tipasa". Revue Africaine, XCII; pp. 1-68.

- 1954: Contribution à l'etude de l'expansion carthaginoise au Maroc. París.

- 1959: "Materiaux de construction employés à Carthage". Karthago 10; pp. 137-139.

- 1970: Manuel d'Archeologie Punique I. París.

- 1976: Manuel d'Archeologie Punique II. París.

Cruz Andreotri, G. y Wulff Alonso, F. (1992): "Fenicios y griegos en la historiografía ilustrada española: Masdeu”. Rivista di Studi Fenici XX, 2. Roma; pp. 161-174.

Davis, N. (1861): Carthage and her remains. Londres.

De LAURIere, B. (1874): Deux Mausoleés africains. Le Médracen et la Tombeau de la Chrétienne. Bulletin Monumental. $5^{\text {ème }}$ Serie II. París; pp. 305-346.

Delattre, A.L.

- 1890: Les tombeaux puniques de Carthage. Lyon.

- 1895: La necrópole punique de Douimès. París.

1905: La necrópole des Rabs, prêtres et prêtresses de Carthage. París.

Desanges, J. y Lancel, S.

- 1984: Bibliographie analytique de l'Afrique Antique XV. Roma. - 1986: Bibliographie analytique de l'Afrique Antique XVI. Roma. FANTAR, M.H.

-1993: Carthage. Approche d'une civilisation; 2 vols. Túnez.

-1995: "Les études phéniciennes et puniques en Tunisie à travers des experiences personelles". I Fenici, ieri oggi domani. Roma; pp. 317-326.

FALBE, C.T. (1833): Recherches sur l'emplacement d Carthage. París.

Fernández de Avilés y Álvarez-Ossorio, A. (1942): "El aparejo irregular de algunos monumentos marroquíes y su relación con el de Toya". Archivo Español de Arqueología XV; pp. 344-347. Madrid.

Ferrer Albelda, E.

- 1996: La España cartaginesa. Claves historiográficas para la Historia de España. Sevilla. 
- 1998a: "Suplemento al mapa paleoetnológico de la Península Ibérica: los púnicos de Iberia". Rivista di Studi Fenici XXVI, 1. Roma; pp. 31-54.

- 1998b: "Los Púnicos de Iberia y la Historiografía Grecolatina". SPAL, Revista de Prehistoria y Arqueología $n^{0}$ 5, 1996. Universidad de Sevilla. Sevilla; pp. 115-131.

Gala Vela, C. (1986): "La figura de Aníbal en una historia española del siglo XVII". Rivista di Studi Fenici XIV, 2. Roma; pp. 229-249.

García y Bellido, A. (1942): Fenicios y cartagineses en Occidente. Madrid.

Gauckler, P. (1915): Nécropoles puniques de Carthage. París. GSELL, S.

- 1901: Les monuments antiques de l'Algerie. 2 vols. París.

- 1923-28: Historie Ancienne de l'Afrique du Nord. 8 vols. París.

- 1926: Promenades Archéologiques aux environs d'Alger (Cherchel, Tipasa, le Tombeau de la Chrétienne). París

JoDIN, A.

- 1966: Mogador. Comptoir phénicien du Maroc atlantique. Rabat.

- 1975: "Recherches sur la métrologie du Maroc punique et hellénistique". Mauretania Antiqua. Etudes Antiques. Tánger.

- 1987: Volubilis Regia Iubae. Contribution à l'étude des civilisations du Maroc antique preclaudien. París.

- 1988: "Les phéniciens à Mogador". Les dossiers, Histoire et Archéologie $n^{0}$ 132. Dijon; pp. 88-91.

KrIngs, V. ed. (1995): La civilisation phénicienne E̊ punique. Manuel de recherche. Leiden.

LANCEL, S.

- 1994: Cartago. Barcelona.

- 1995a: "L'Archéologie monumentale partim Occident". En Krings, V. (ed.) La civilisation phénicienne Ẽ punique. Manuel de recherche. Leiden; pp. 132-135.

- 1995b: "Vie des cités et urbanisme partim Occident". En Krings, V. (ed.) La civilisation phénicienne Ẻ punique. Manuel de recherche. Leiden; pp. 370-377.

- 1995c: "Architecture militaire, civile et domestique partim Occident". En Krings, V. (ed.) La civilisation phénicienne $\mathcal{E}$ punique. Manuel de recherche. Leiden; pp. 397-411.

LeZine, A.

- 1959: "Resistance à l'hellénisme de l'architecture religieuse de Carthage". Les cahiers de Tunisie 26-27. Túnez; pp. 247-261.
- 1961: Architecture punique. Túnez

- 1968: Carthage, Utique, études de architecture et urbanisme. París.

Lefebvre, G. (1974): El nacimiento de la historiografía moderna. Barcelona.

LipInski, E. (ed.) (1992): Dictionnaire de la civilisation phénicienne et punique. París.

LÓPEZ CASTRO, J.L.

- 1992: "La colonización fenicia en el sur de la Península Ibérica. 100 años de investigación”. La colonización fenicia en el sur de la Península Ibérica. 100 años de investigación. Almería; pp.11-79.

- 1994: "Cartago y la Península Ibérica en la historiografía española reciente”. Hispania Antiqua XVIII, II. Valladolid; pp.519-532.

- 1995: Hispania Poena. Los fenicios en la Hispania romana. Barcelona.

Maier, J. (1992): "La necrópolis de "La Cruz del Negro" (Carmona, Sevilla): Excavaciones de 1900 a 1905". Cuadernos de Prehistoria y Arqueología de la Universidad Autónoma de Madrid, 19. Madrid; pp. 95-119.

Mariana, J. de (1592): Historia de rebus Hispaniae. Versión Las Glorias Nacionales. 1852-1854. Madrid

Merlin, A. y Drappier, L. (1909): La Nécropole punique d'Ard el-Kheraïb. París.

Moscati, S.

- 1983: Cartagineses. Madrid.

- 1986: Italia punica. Milán.

- 1988: (dir.). Los fenicios. Barcelona.

PERICOT, L. (1934): Historia de España. Gran historia general de los pueblos hispánicos. Barcelona.

PiCARD, G. Ch. y C. Ch. (1958): La vie quotidienne à Carthage. París

Prados Martínez, F.

- 2000a: "La Arqueología Púnica. El descubrimiento de una cultura y el nacimiento de una disciplina científica". Arqueologia Peninsular. História, Teoria e Prática. Actas do $3^{\circ}$ Congresso de Arqueologia Peninsular, Vol. 1. Oporto; pp. 301-310.

- 2000b: El desarrollo de la viticultura y el consumo del vino en el ámbito cartaginés". Espacio, Tiempo y Forma, Serie III, Historia Antigua. 13. Madrid; pp. 45-64.

- 2001: "La democratización de la muerte en el mundo púnico. Las necrópolis de Kerkouane (Túnez)". Revista de Arqueología no 241. Madrid; pp. 28-39. 
- 2003: Del Monte Líbano a las Columnas de Hércules. Madrid.

Quintero Atauri, P. (1917): Cádiz. Primeros Pobladores. Cádiz.

Roldán Gómez, L.; Bendala Galán, M.; Blánguez Péres, J. y Martínez Lillo, S. (1998): Carteia. Madrid.

Ruiz Mata, D. (1998): "Fenicios en el Sur Peninsular: Sucinta reseña historiográfica y propuesta de objetivos de investigación en los albores del año 2000". Albor, $\mathrm{n}^{\circ}$ 635-636. Madrid.

Schulten, A.

- 1929: Hispania. Barcelona.

- 1945: Tartessos. Madrid.

SiRET, L. (1908): Villaricos y Herrerías. Antigüedades púnicas, romanas, visigóticas y árabes. Memorias de la Real Academia de la Historia. Madrid.

\section{TARRADELL, M.}

- 1951: "Las excavaciones en Lixus (Marruecos)". Ampurias XII; pp. 186-189.

- 1960: Marruecos Púnico. Tetuán.

TEIXIDOR, J. (1994): "Los cartagineses entre Aristóteles y Polibio". El mundo púnico. Historia, sociedad y cultura. Murcia; pp.131-139.

Thouvenot, R. (1949): Volubilis. París.

TLati, S-E., (1978): La Carthage Punique. Túnez.

VV.AA. (1991): Historiografía de la Arqueología y de la Historia Antigua de España (Siglos XVIII-XX). Madrid.

VILLE, G. (1968): Dictionnaire d'Archeologie Larousse, pág. 6.

Vuillemot, G. (1965): Reconnaissances aux échelles puniques d'Oranie. Autun.

Whitaker, Y.I. (1921): Motya. A Phoenician colony in Sicily. Londres. 